\title{
Berat Badan Lahir Rendah (BBLR) sebagai Determinan Terjadinya ISPA pada Balita Analisis Data SDKI Tahun 2017
}

\author{
Low Birth Weight (LBW) as a Determinant of ARI in Among Children Under Five \\ Age based on Analysis of IDHS in 2017
}

\author{
Desinta Ayu Lestari ${ }^{\mathrm{a}^{*}}$, Asri C. Adisasmita ${ }^{\mathrm{b}}$ \\ $\mathrm{a}^{*}$ Magiter Prodi Epidemiologi Fakultas Kesehatan Masyarakat Universitas Indonesia, Lantai 1 Gedung A, Kampus UI Depok, Indonesia \\ ${ }^{\mathrm{b}}$ Departemen Epidemiologi, Fakultas Kesehatan Masyarakat Universitas Indonesia, Lantai 1 Gedung A, Kampus UI Depok, Indonesia
}

A B S T R A K

Infeksi Saluran Pernapasan Akut (ISPA) yaitu penyakit infeksi yang secara umum ada pada anak usia balita. ISPA diartikan sebagai penyakit saluran pernapasan akut yang disebabkan oleh agen infeksius yang menularkan diantara manusia. ISPA merupakan faktor morbidtas dan mortalitas utama pada Balita. Faktor risiko terjadinya ISPA pada balita salah satunya yaitu BBLR. Jenis penelitan dalam penelitian ini adalah korelasional. Metode penelitian dalam penelitian ini menggunakan cross sectional dengan analisis cox regression dan hasil ukur Risk ratio (RR). Populasi pada penelitian ini sebanyak 17.848 responden dan sampel yang memenuhi kriteria penelitian sebanyak 13.113 responden. Pelaksanaan penelitian dilakukan pada bulan Mei Juli 2020. Variabel pada penelitian ini meliputi umur balita, jenis kelamin, pendidikan ibu dan ayah, pekerjaan ibu dan ayah, status merokok ibu dan ayah, status imunisasi, pemberian ASI, pemberian vitamin A, tempat tinggal, tingkat kesejahteraan keluarga dan jumlah balita dalam keluarga. Hasil penelitian ini ditemukan hubungan signifikan BBLR tehadap kejadian ISPA pada balita usia 0 - 59 bulan dengan pvalue 0,046 dan nilai RR adjusted 1,14 kali (95\% CI 1,00 - 1,31) setelah dikontrol oleh variable jenis kelamin, usia bayi, tingkat kesejahteraan keluarga, pekerjaan ibu dan imunisasi. Penelitian ini ditemukan adanya hubungan signifikan BBLR terhadap ISPA setelah dikontrol oleh variabel confounding jenis kelamin, tingkat kesejahteraan keluarga, pekerjaan ibu dan imunisasi. Oleh karena itu, pentingnya informasi dari tenaga kesehatan bahwa nutrisi ibu saat hamil penting untuk mencegah bayi terlahir BBLR disertai pemberian imunisasi lengkap pada balita untuk mencegah balita mengalami ISPA.

Kata Kunci: ISPA, BBLR, Imunisasi

\section{A B S T R A C T}

Acute Respiratory Infection (ISPA) is an infectious disease that generally occurs in children under five. ARI is defined as an acute respiratory disease caused by an infectious agent that transmits between humans. ARI is a major morbidity and mortality factor in children under five. One of the risk factors for the occurrence of ARI in children under five is LBW. The type of research in this study is correlational. The research method used in this study was cross sectional with cox regression analysis and the results of measuring the risk ratio (RR). The population in this study were 17,848 respondents and the sample that met the research criteria was 13,113 respondents. The research was carried out in May July 2020. The variables in this study included age of children under five, gender, education of mothers and fathers, occupation of mothers and fathers, smoking status of mothers and fathers, immunization status, breastfeeding, giving vitamin A, place of residence, the level of family welfare and the number of children under five in the family. The results of this study found a significant relationship of LBW to the incidence of ARI in children aged 0 - 59 months with a p-value of 0.046 and an adjusted RR value of 1.14 times (95\% CI 1.00 - 1.31) after being controlled by variables of gender, infant age, level of family welfare, maternal occupation and immunization. This study found a significant association of LBW to ARI after being controlled by confounding variables of gender, family welfare level, maternal occupation and immunization. Therefore, the importance of information from health workers that maternal nutrition during pregnancy is important to prevent babies from being born LBW accompanied by complete immunization for infant to prevent infant from experiencing ARI.

Key words: ARI, LBW, Immunization

sekitar 30-50\% dan 20-40\% pada rumah sakit. ${ }^{2}$ Di kota Gulbarga, India insiden ISPA sebanyak 27,25\% dengan angka proporsi balita umur 0-1 tahun sebesar $38,4 \%$ sedangkan balita umur 2-3 tahun sebesar 37,84\%. ${ }^{3}$ Angka prevalensi ISPA nasional di Indonesia tahun 2013 berdasarkan keluhan dan diagnosis dari tenaga kesehatan yaitu sebesar 25,0 persen. ${ }^{4}$

Berat badan lahir rendah adalah penanda pengganti gangguan pertumbuhan intrauterin, yang

*Korespondensi: Desinta Ayu Lestari, Magister Prodi Epidemiologi Fakultas Kesehatan Masyarakat Universitas Indonesia. Email: the_ayrie@gmail.com 
menyebabkan gangguan imunokompetensi dan fungsi anatomi paru-paru yang buruk di antara bayi. ${ }^{5,6}$ BBLR berakibat pada bayi adalah daya tahan tubuh terhadap penyakit infeksi menjadi rendah, perkembangan dan pertumbuhan terhambat, tingkat kematian lebih tinggi dan mudah mengalami gangguan pernafasan, hal ini disebabkan oleh otot pada pernafasan yang lemah dan perkembangan paru - paru yang belum sempurna. ${ }^{7}$

Beberapa faktor terjadinya ISPA pada balita yaitu jenis kelamin, usia bayi, imunisasi, pendidikan orang tua, status merokok orang tua, pemberian ASI, pemberian vitamin A dan salah satunya BBLR. Penelitian di Antalya, Turki bahwa bayi lahir dengan BBLR berisiko untuk terkena ISPA sebesar 1,5 kali (RR 1,5 95\% CI 1.22-1.85). ${ }^{8}$ Penelitian lain Washington bayi dengan riwayat BBLR memiliki peluang risiko sebesar 1,83 kali ( $R R$ 1,83 95\% CI = 1.28-2.62) mengalami ISPA bila dibandingkan dengan yang berat lahirnya normal. ${ }^{9}$ Penelitian di Beijing hospital bahwa balita dengan MLBW (Medium Low Birth Weight) memiliki risiko sebesar 5,73 kali (95\% CI 1,66-19,81) untuk terkena ISPA bila dibandingkan dengan balita yang lahir dengan berat normal. ${ }^{10}$

\section{Metode}

Desain penelitian dalam penelitian ini adalah analitik dengan pendekatan cross sectional. Penelitian ini menggunakan data sekunder Survei Demografi Kesehatan Indonesia (SDKI) tahun 2017. SDKI tahun 2017 merupakan survei rumah tangga berskala nasional dan dilaksanakan di seluruh wilayah Indonesia di 33 provinsi di Indonesia. Waktu penelitian ini dilakukan pada Agustus 2017. Populasi pada penelitian ini yaitu balita dari wanita usia subur yang direkrut dalam wawancara survei SDKI 2017 yaitu sebanyak 17.848 wanita usia subur yang bersedia untuk diwawancarai dan menjadi responden pada survei SDKI tahun 2017. Teknik pengambilan sampel menggunakan multistage random sampling. Jumlah sampel dalam penelitian ini sebanyak 13.113 responden. Variabel yang diteliti berupa BBLR, ISPA, umur balita, jenis kelamin, usia ibu, pendidikan ibu, pendidikan ayah, pekerjaan ibu, pekerjaan ayah, status merokok ibu, status merokok ayah, status imunisasi, pemberian ASI, pemberian vitamin A, tempat tinggal, tingkat kesejahteraan keluarga dan jumlah balita dalam keluarga. Analisis yang digunakan yaitu logistic regression dengan ukuran asosiasi risk ratio (RR).

\section{Hasil}

Berdasarkan tabel 1 terlihat insiden ISPA yaitu sebanyak 3.084 kasus $(23,5 \%)$ sedangkan yang tidak
Tabel 1 Distribusi Frekuensi Variabel Penelitian

\begin{tabular}{|c|c|c|}
\hline Variabel & Jumlah (n) & $\%$ \\
\hline \multicolumn{3}{|l|}{ ISPA } \\
\hline $\mathrm{Ya}$ & 3.084 & 23,5 \\
\hline Tidak & 10.029 & 76,5 \\
\hline \multicolumn{3}{|l|}{ B B L R } \\
\hline $\mathrm{Ya}$ & 1.516 & 11,6 \\
\hline Tidak & 11.597 & 88,4 \\
\hline \multicolumn{3}{|l|}{ U m ur } \\
\hline $0-5$ bulan & 1.439 & 11,0 \\
\hline $6-11$ bulan & 1.491 & 11,4 \\
\hline $12-23$ bulan & 2.966 & 22,6 \\
\hline $24-35$ bulan & 2.635 & 20,1 \\
\hline $36-59$ bulan & 4.582 & 65,1 \\
\hline \multicolumn{3}{|l|}{ Jenis Kelam in } \\
\hline Laki-laki & 6.724 & 51,3 \\
\hline Perempuan & 6.389 & 58,7 \\
\hline \multicolumn{3}{|l|}{ Status Imunisasi } \\
\hline Tidak imunisasi \& Tidak lengkap & 6.261 & 74,9 \\
\hline Lengkap & 2.094 & 25,1 \\
\hline \multicolumn{3}{|l|}{ Pemberian ASI } \\
\hline Disusui sampai saat survey (usia $>6$ bulan) & 3.620 & 27,6 \\
\hline Disusui sampai saat survey (usia $\leq 6$ bulan) & 1.444 & 11,0 \\
\hline Pernah disusui tp sekarang tdk (usia $>6$ bulan) & 7.382 & 56,3 \\
\hline Pernah disusuitp sekarang tdk (usia $\leq 6$ bulan & 172 & 1,3 \\
\hline Tidak pernah disusui sama sekali & 491 & 3,7 \\
\hline \multicolumn{3}{|l|}{ Pemberian Vitamin A } \\
\hline Tidak diberi Vit A \& Diberi Vit A tdk sesuai usia & 10.428 & 81,6 \\
\hline Diberi Vit A sesuai usia & 2.352 & 18,4 \\
\hline \multicolumn{3}{|l|}{ Jum lah Balita dalam Keluarga } \\
\hline$\geq 2$ balita & 3.222 & 24,6 \\
\hline$\leq 2$ balita & 9.981 & 75,4 \\
\hline \multicolumn{3}{|l|}{ Pendidikan Ibu } \\
\hline Tidak Sekolah & 82 & 0,6 \\
\hline Pendidikan Dasar & 2.885 & 22,0 \\
\hline Pendidikan Menengah & 7.664 & 58,4 \\
\hline Pendidikan Tinggi & 2.482 & 18,9 \\
\hline \multicolumn{3}{|l|}{ Pendidikan Ayah } \\
\hline Tidak Sekolah & 138 & 2,1 \\
\hline Pendidikan Dasar & 2.065 & 30,8 \\
\hline Pendidikan Menengah & 3.574 & 53,2 \\
\hline Pendidikan Tinggi & 935 & 13,9 \\
\hline \multicolumn{3}{|l|}{ Pekerjaan Ayah } \\
\hline Tidak bekerja & 99 & 0,8 \\
\hline Pekerjaan Informal (blue collar) & 10.197 & 81,3 \\
\hline Pekerjaan Formal (white collar) & 2.247 & 17,9 \\
\hline \multicolumn{3}{|l|}{ Pekerjaan Ibu } \\
\hline Tidak bekerja & 6.140 & 50,3 \\
\hline Pekerjaan Informal (blue collar) & 4.266 & 34,9 \\
\hline Pekerjaan Formal (white collar) & 1.810 & 14,8 \\
\hline \multicolumn{3}{|l|}{ Frekuensi Merokok Ibu } \\
\hline Setiap hari \& kadang - kadang & 190 & 1,4 \\
\hline Tidak Pernah & 12.921 & 98,6 \\
\hline \multicolumn{3}{|l|}{ Frekuensi Merokok Ayah } \\
\hline Setiap hari \& kadang - kadang & 4.768 & 71,1 \\
\hline Tidak Pernah & 1.942 & 28,9 \\
\hline \multicolumn{3}{|l|}{ Daerah Tempat Tinggal } \\
\hline Rural (Pedesaan) & 6.270 & 47,8 \\
\hline Urban (Perkotaan) & 6.843 & 52,2 \\
\hline \multicolumn{3}{|l|}{ Tingkat Kesejahteraan Keluarga } \\
\hline Paling Miskin & 2.880 & 22,0 \\
\hline Miskin & 2.629 & 20,0 \\
\hline Menengah & 2.616 & 19,9 \\
\hline Kay a & 2.548 & 19,4 \\
\hline Paling Kaya & 2.440 & 18,6 \\
\hline
\end{tabular}


ISPA sebanyak 10.029 (76,5\%). Proporsi bayi dengan BBLR yaitu berat lahir < 2.500 gram sebanyak 1.516 bayi $(11,6 \%)$ sedangkan bayi dengan berat lahir normal $\geq 2.500$ gram sebanyak 11.597 bayi $(88,4 \%)$.
Berdasarkan hasil analisis bivariat pada tabel 2 diatas terlihat bahwa bayi laki - laki beresiko 1,10 kali (95\% CI 1,01 - 1,19) mengalami ISPA dibandingkan dengan bayi perempuan dan hasil statistik pvalue 0,018

Tabel 2 Hasil Bivariat Faktor Resiko terhadap ISPA pada Balita

\begin{tabular}{|c|c|c|c|c|c|c|c|}
\hline \multirow{3}{*}{ Variabel } & \multicolumn{4}{|c|}{ ISPA } & \multirow{3}{*}{$\mathbf{R R}$} & \multirow{3}{*}{ CI95\% } & \multirow{3}{*}{$\begin{array}{c}\text { p- } \\
\text { value }\end{array}$} \\
\hline & \multicolumn{2}{|c|}{ Ya, ISPA } & \multicolumn{2}{|c|}{ Tidak ISPA } & & & \\
\hline & n & $\%$ & $\mathbf{n}$ & $\%$ & & & \\
\hline \multicolumn{8}{|l|}{ BBLR } \\
\hline Ya & 407 & 26,8 & 1.109 & 73,2 & 1,223 & $1,083-1,381$ & $0,001^{*}$ \\
\hline Tidak & 2.667 & 23,1 & 8.920 & 76,9 & Reff & & \\
\hline \multicolumn{8}{|l|}{ Jenis Kelamin } \\
\hline Laki - Laki & 1.639 & 24,4 & 5.085 & 75,6 & 1,103 & $1,017-1,196$ & $0,018^{*}$ \\
\hline Perempuan & 1.445 & 22,6 & 4.944 & 77,4 & Reff & & \\
\hline \multicolumn{8}{|l|}{ Usia } \\
\hline 0-5 Bulan & 166 & 11,5 & 1.273 & 85,5 & 0,453 & $0,379-0,540$ & $0,000^{*}$ \\
\hline 6-11 Bulan & 396 & 26,6 & 1.095 & 73,4 & 1,255 & $1,097-1,435$ & $0,001^{*}$ \\
\hline 12-23 Bulan & 829 & 28,0 & 2.137 & 72,0 & 1,346 & $1,211-1,497$ & $0,000^{*}$ \\
\hline 24-35 Bulan & 668 & 25,4 & 1.967 & 74,6 & 1,179 & $1,054-1,318$ & $0,004^{*}$ \\
\hline 36-59 Bulan & 1.025 & 22,4 & 3.557 & 77,6 & Reff & & \\
\hline \multicolumn{8}{|l|}{ Status Imunsasi } \\
\hline $\begin{array}{l}\text { Tidak Imunisasi \& Tidak } \\
\text { Lengkap }\end{array}$ & 1.528 & 24,4 & 4.733 & 75,6 & 1,060 & $0,957-1,175$ & 0,263 \\
\hline Lengkap & 482 & 23,0 & 1.612 & 77,0 & Reff & & \\
\hline \multicolumn{8}{|l|}{ Pemberian ASI } \\
\hline ASI Exposed & 148 & 22.3 & 515 & 77,7 & 0,931 & $0,772-1,123$ & 0,454 \\
\hline ASI Non Exposed & 2.936 & 23,6 & 9.510 & 76,4 & Reff & & \\
\hline \multicolumn{8}{|l|}{ Pemberian Vitamin A } \\
\hline $\begin{array}{l}\text { Tidak di beri Vit A \& Vit A tdk } \\
\text { sesuai umur }\end{array}$ & 2.441 & 23,4 & 7.987 & 76,6 & 0,923 & $0,832-1,024$ & 0,131 \\
\hline Vit A sesuai umur & 585 & 24,9 & 1.767 & 75,1 & Reff & & \\
\hline \multicolumn{8}{|c|}{ Jumlah Balita dalam Keluarga } \\
\hline$=2$ Balita & 750 & 23,3 & 2.472 & 76,7 & 0,982 & $0,894-1,079$ & 0,710 \\
\hline$<2$ Balita & 2.334 & 23,6 & 7.557 & 7643 & Reff & & \\
\hline \multicolumn{8}{|l|}{ Pendidikan Ibu } \\
\hline Tidak Sekolah & 17 & 20,7 & 65 & 79,3 & 1,074 & $0,624-1,849$ & 0,796 \\
\hline Pendidikan Dasar & 733 & 25,4 & 2.152 & 74,6 & 1,399 & $1,229-1,593$ & $0,000^{*}$ \\
\hline Pendidikan Menengah & 1.848 & 24,1 & 5.816 & 75,9 & 1,305 & $1,167-1,460$ & $0,000^{*}$ \\
\hline Pendidikan Tinggi & 486 & 19,6 & 1.996 & 80,4 & Reff & & \\
\hline Pendidikan Ayah & & & & & & & \\
\hline Tidak Sekolah & 25 & 18,1 & 113 & 81,9 & 0,755 & $0,477-1,195$ & 0,229 \\
\hline Pendidikan Dasar & 456 & 22,1 & 1.609 & 77,9 & 0,967 & $0,803-1,163$ & 0,718 \\
\hline Pendidikan Menengah & 799 & 22,4 & 2,775 & 77,6 & 0,982 & $0,827-1,166$ & 0,836 \\
\hline Pendidikan Tinggi & 212 & 22,7 & 723 & 77,3 & Reff & & \\
\hline Pekerjaan Ibu & & & & & & & \\
\hline Tidak bekerja & 1.424 & 23,2 & 4.716 & 76,8 & 1,238 & $1,086-1,410$ & $0,001^{*}$ \\
\hline Pekerjaan Informal & 1.082 & 25,4 & 3.184 & 74,6 & 1,393 & $1,217-1,594$ & $0,000^{*}$ \\
\hline Pekerjaan Formal & 355 & 19,6 & 1.445 & 80,4 & Reff & & \\
\hline Pekerjaan Ayah & & & & & & & \\
\hline Tidak bekerja & 25 & 25,3 & 74 & 74,7 & 1,349 & $0,847-2,148$ & 0,207 \\
\hline Pekerjaan Informal & 2.492 & 24,4 & 7.705 & 75,6 & 1,292 & $1,154-1,446$ & $0,000^{*}$ \\
\hline Pekerjaan Formal & 450 & 20,0 & 1.797 & 80,0 & Reff & & \\
\hline Frekuensi Merokok Ibu & & & & & & & \\
\hline Setiap Hari \& Kadang - kadang & 41 & 21,6 & 149 & 78,4 & 0,893 & $0,631-1,265$ & 0,525 \\
\hline Tidak Pernah & 3.043 & 23,6 & 9.878 & 76,4 & Reff & & \\
\hline Frekuensi Merokok Ayah & & & & & & & \\
\hline Setiap Hari \& Kadang - kadang & 1.069 & 22,4 & 3.699 & 77,6 & 1,038 & $0,914-1,179$ & 0,568 \\
\hline Tidak Pernah & 423 & 21,8 & 1.519 & 78,2 & Reff & & \\
\hline Daerah Tempat Tinggal & & & & & & & \\
\hline Rural (Pedesaan) & 1.533 & 24,4 & 4.737 & 75,6 & 1,104 & $1,019-1,197$ & $0,016^{*}$ \\
\hline Urban (Perkotaan) & 1.551 & 22,7 & 5.292 & 77,3 & Reff & & \\
\hline Tingkat Kesejahteraan Kelua & arga & & & & & & \\
\hline Paling Miskin & 733 & 25,5 & 2.147 & 74,5 & 1,526 & $1,337-1,743$ & $0,000^{*}$ \\
\hline Miskin & 648 & 24,6 & 1.981 & 75,4 & 1,462 & $1,277-1,675$ & $0,000^{*}$ \\
\hline Menengah & 658 & 25,2 & 1.958 & 74,8 & 1,502 & $1,312-1,720$ & $0,000^{*}$ \\
\hline Kaya & 599 & 23,5 & 1.949 & 76,5 & 1,374 & $1,197-1,577$ & $0,000^{*}$ \\
\hline Paling Kaya & 466 & 18,3 & 1.994 & 81,7 & Reff & & \\
\hline
\end{tabular}


bahwa terdapat hubungan yang bermakna. Usia bayi 6 - 11 bulan beresiko 1,2 kali (95\% CI 1,09 - 1,43) mengalami ISPA dibandingkan usia 12 - 23 bulan dengan pvalue 0,000 sehingga hasil ini menunjukkan ada hubungan bermakna secara statistik. Status Imunisasi, pemberian ASI dan pemberian vitamin A tidak terdapat hubungan yang signifikan karena pvalue $>0,05$. Pendidikan ibu dasar berisiko sebesar 1,4 kali (95\% CI 1,22 - 1,59) balitanya mengalami ISPA dibandingkan ibu yang pendidikannya menengah hasil ini menunjukkan hubungan bermakna secara statistik dengan pvalue 0,000 . Ibu yang tidak bekerja balitanya beresiko terkena ISPA sebesar 1,2 kali (95\% CI 1,1 1,4) dibandingkan ibu yang bekerja informal, hasil ini menunjukkan ada hubungan bermakna secara statistik dengan pvalue 0,001 . Ayah yang bekerja informal balitanya beresiko terkena ISPA sebesar 1,2 kali (95\% CI 1,15 - 1,44) dibandingkan ayah yang bekerja secara formal, hasil menunjukkan bahwa ada hubungan bermakna secara statistik dengan pvalue 0,000. Frekuensi ibu merokok dan frekuensi ayah merokok tidak terdapat hubungan yang signifikan karena pvalue $>0,05$. Daerah tempat tinggal di pedesaan (rural) memiliki risiko balitanya terkena ISPA sebesar 1,1 kali (95\% CI 1,01 - 1,19) dibandingkan daerah tempat tinggal di perkotaan (urban). Hasil ini menunjukkan hubungan bermakna secara statistik dengan pvalue 0,016. Tingkat kesejahteraan keluarga miskin beresiko untuk balitanya terkena ISPA sebesar 1,4 kali (95\% CI 1,27 - 1,67) dibandingkan keluarga menengah.

Tabel 3 Model Akhir Analisis Multivariat BBLR terhadap ISPA

\begin{tabular}{|c|c|c|c|}
\hline Variabel & $\mathbf{R R}$ & $95 \% \mathrm{CI}$ & P-value \\
\hline \multicolumn{4}{|l|}{ Variabel Independen } \\
\hline BBLR & 1,147 & $1,003-1,313$ & 0,046 \\
\hline BBL Normal & & 1 & \\
\hline \multicolumn{4}{|l|}{ Variabel Kovariat } \\
\hline \multicolumn{4}{|l|}{ Jenis Kelamin } \\
\hline Laki - Laki & 1,112 & $1,016-1,218$ & 0,021 \\
\hline Perempuan & & 1 & \\
\hline \multicolumn{4}{|l|}{ Usia Bayi } \\
\hline $0-5$ bulan & 0,469 & $0,392-0,561$ & 0,000 \\
\hline $6-11$ bulan & 1,063 & $0,931-1,215$ & 0,366 \\
\hline $12-23$ bulan & 1,111 & $0,997-1,238$ & 0,058 \\
\hline $24-35$ bulan & & 1 & \\
\hline \multicolumn{4}{|l|}{ Tingkat Kesejahteraan } \\
\hline \multicolumn{4}{|l|}{ Keluarga } \\
\hline Paling Miskin & 1,321 & $1,131-1,544$ & 0,000 \\
\hline Miskin & 1,315 & $1,122-1,540$ & 0,001 \\
\hline Menengah & 1,322 & $1,129-1,550$ & 0,001 \\
\hline Kaya & 1,266 & $1,080-1.484$ & 0,004 \\
\hline Paling Kaya & & 1 & \\
\hline \multicolumn{4}{|l|}{ Pekerjaan Ibu } \\
\hline Tidak Bekerja & 1,140 & $0,983-1,322$ & 0,082 \\
\hline $\begin{array}{l}\text { Pekerjaan Informal } \\
\text { (Blue Collar) }\end{array}$ & 1,260 & $1,079-1,472$ & 0,004 \\
\hline $\begin{array}{l}\text { Pekerjaan Formal } \\
\text { (White Collar) }\end{array}$ & & 1 & \\
\hline \multicolumn{4}{|l|}{ Imunisasi } \\
\hline $\begin{array}{l}\text { Tidak Imunisasi \& } \\
\text { Tidak Lengkap }\end{array}$ & 1,079 & $0,968-1,202$ & 0,170 \\
\hline Lengkap & & 1 & \\
\hline
\end{tabular}

Hasil dari analisis regresi logistik (tabel 3) menujukkan bahwa 5 variabel yang berhubungan secara signifikan dengan pengaruh BBLR terhadap ISPA yaitu jenis kelamin, usia bayi, tingkat kesejahteraan keluarga, pekerjaan ibu dan imunisasi. Jenis kelamin bayi laki-laki beresiko untuk terkena ISPA sebanyak 1,1 kali $(95 \%$ CI 1,02 - 1,21) dibandingkan dengan bayi perempuan, Usia bayi 0-5 bulan justru memprotektif terhadap ISPA sebesar 0,5 kali dibandingkan bayi usia 6-11 bulan, Keluarga miskin beresiko 1,3 kali (95\% CI 1,13 - 1,54) untuk mengalami ISPA bila dibandingkan dengan keluarga dari golongan menengah, ibu yang bekerja informal beresiko balitanya mengalami ISPA sebanyak 1,2 kali (95\% CI 1,07 - 1,47) bila dibandingkan dengan ibu yang bekerja secara formal, balita yang tidak di imunisasi dan imunisasi tidak lengkap beresiko sebesar 1,07 kali (95\% CI 0,96 - 1,20) untuk terkena ISPA bila dibandingkan dengan balita yang di imunisasi namun hasil ini tidak signifikan karena pvalue > 0,05. Kesimpulannya adalah Balita dengan BBLR beresiko sebesar 1,15 kali (95\% CI 1,003 - 1,313) untuk mengalami ISPA dibandingkan balita dengan berat lahir normal setelah di kontrol oleh variabel kovariat jenis kelamin, usia bayi, tingkat kesejahteraan keluarga, pekerjaan ibu dan imunisasi.

\section{Pembahasan}

Pada penelitian ini ada keterbatasan dan kelemahan penelitian yang berpengaruh terhadap hasil penelitan. Penelitian ini menggunakan Survei Demografi Kesehatan Indonesia tahun 2017 dengan pengambilan variabel mengikuti ketersediaan dan kesesuaian data. Pada variabel penelitian ini tidak memiliki semua data lengkap. Pada penelitian inipun kasus kejadian ISPA berdasarkan wawancara ibu dari si anak yang diwawancarai bukan dengan diagnosis dokter maupun ahli kesehatan lainnya. Bias seleksi pada penelitian ini minim terjadi karena pada penelitian ini sampel penelitian di dapatkan 13.113 dari populasi eligible 14.211 yaitu $92,2 \%$ participation rate $<20 \%$ sehingga tidak terjadi bias seleksi. Dalam penelitian ini memungkinkan adanya misklasifikasi non differensial seperti dalam variabel ISPA mengingat batuk, demam maupun sesak nafas dalam 2 minggu terakhir dan pada variabel frekuensi merokok menjawab dengan pertanyaan setiap hari, kadang - kadang yang tidak dapat di ukur tepat apakah kadang - kadang itu berapa kali dalam seminggu atau sebulan sehingga hasil penelitian ini cenderung underestimate. Berdasarkan hasil analisis yang telah dilakukan tidak adanya bias seleksi dan hanya memungkinkan adanya misklasifikasi non differ ensial maka, bisa disimpulkan bahwa hasil 
ini pula dapat digeneralisasikan pada populasi eligible dan populasi sumber. Selain itu penelitian ini bisa digeneralisasikan ke populasi lain dengan karakteristik sampel yang sama pada penelitian ini.

Pada penelitian ini diperoleh proporsi kejadian ISPA pada usia 0 - 59 bulan adalah sebesar $23,5 \%$ bila dibandingkan prevalensi ISPA nasional di Indonesia tahun 2013 yaitu sebasar 25,0\% mengalami penurunan sedikit. Pada hasil riskesdas tahun 2018 ISPA sebesar 4,4\% yang berarti mengalami penurunan jauh dibandingkan sebelumnya. Hasil penelitian ISPA ini lebih rendah bila dibandingkan hasil penelitian insiden ISPA Di kota Gulbarga, India sebanyak $27,25 \%$ dengan angka proporsi balita umur 0-1 tahun sebesar 38,4\% sedangkan balita umur 2-3 tahun sebesar $37,84 \% .^{3}$ Pada penelitian ini diperoleh bahwa proporsi BBLR sebesar 11,6\% bila dibandingkan prevalensi BBLR pada data SDKI tahun 2013 yaitu sebesar 7\% maka ada peningkatan sedikit. Angka prevalensi pada penelitian ini lebih tinggi bila dibandingkan Prevalensi BBLR di RSU Adwa, Ethiopia utara yaitu sebanyak 10\% dari semua kelahiran hidup. ${ }^{11}$ Kemudian, Insiden BBLR di Iran, pada tahun 2012 yaitu sebanyak 6,3\% masih lebih rendah di banding Asia yaitu 19,7\%. ${ }^{12}$ BBLR juga berkaitan erat dengan status gizi ibu saat hamil, status gizi ibu hamil dapat mempengaruhi pertumbuhan dan perkembangan janin. Kekurangan energi kronis pada ibu hamil menyebabkan ibu tidak memiliki cadangan zat gizi yang adekuat untuk kebutuhan fisiologis kehamilan, yaitu meningkatnya volume darah dan juga perubahan hormon untuk pertumbuhan dan perkembangan janin yang dikandung sehingga suplai zat gizi dari ibu ke janin berkurang, akibatnya pertumbuhan dan perkembangan janin terhambat dan bayi lahir dengan berat lahir rendah. ${ }^{13,14}$ Hasil penelitian yang dilakukan oleh Astria di Puskesmas Padang Selasa Palembang tahun 2017 bahwa status gizi ibu hamil yang buruk beresiko 5,76 kali melahirkan bayi dengan BBLR dibandingkan ibu dengan status gizi baik. ${ }^{15}$

Hasil pada penelitian ini pengaruh BBLR terhadap ISPA menujukkan hasil yang signfikan yaitu dengan pvalue 0,04 dengan nilai RR 1,15 kali (95\% CI 1,00 - 1,31) yang berarti bahwa balita dengan BBLR beresiko 1,15 kali untuk mengalami ISPA bila dibandingkan balita yang berat lahirnya normal. Penelitian ini sejalan dengan penelitian lainnya yaitu Penelitian di Washington bayi dengan riwayat BBLR memiliki peluang risiko sebesar 1,83 kali $(95 \% \mathrm{CI}=$ 1.28 - 2.62) mengalami ISPA bila dibandingkan dengan yang berat lahirnya normal. ${ }^{9}$ Penelitian lain di Antalya, Turki bahwa bayi dengan BBLR beresiko terkena ISPA sebesar 1,5 kali (95\% CI 1.22 - 1.85). ${ }^{8}$ Penelitian di Beijing hospital bahwa balita dengan MLBW (Medium Low Birth Weight) memiliki risiko sebesar 5,73 kali
(95\% CI 1,66-19,81) mengalami ISPA dibandingkan dengan balita lahir berat normal. ${ }^{10}$

Penelitian ini juga sejalan dengan penelitian yang telah dilakukan oleh Fibrila di Puskesmas Bumi Mas Kecamatan Batanghari Lampung Timur bahwa balita yang memiliki BBLR beresiko sebesar 4,5 kali (95\% CI 1,26 - 16,0) untuk mengalami ISPA bila dibandingkan balita BB lahir normal ${ }^{16}$ Hasil penelitian ini tidak sejalan dengan habibi, et al bahwa BBLR terhadap ISPA tidak adanya hubungan yang bermakna secara statistik. ${ }^{17}$ Dan tidak sejalan dengan penelitian Christi, et al, bahwa tidak ada hubungan kejadin BBLR terhadap ISPA yaitu pvalue $0,137>0,05 .{ }^{18}$ Bayi atau balita yang BBLR berisiko kematian lebih tinggi dibanding bayi atau balita saat lahir dengan berat normal, terutama pada bulan - bulan pertama kehidupannya karena proses pembentukan anti bodi tubuh yang tidak maksimal menjadi lebih rentan terhadap penyakit infeksi, seperti saluran pernafasan dan pneumonia. ${ }^{19}$ Pada penelitian ini, variabel kovariat lain yang juga ada hubungan bermakna terhadap kejadian ISPA yaitu balita berjenis kelamin laki - laki lebih berisiko mengalami ISPA sebesar 1,1 kali (95\% CI 1,02 - 1,21) dibandingkan balita perempuan. Hasil pada penelitian inipun tidak sejalan pada penelitian yang dilakukan oleh (Christi, Rahayuning and Nugraheni, 2015) bahwa tidak ada hubungan yang signfikan antara jenis kelamin terhadap ISPA. ${ }^{18}$ Pada penelitian ini imunisasi tidak berhubungan signifikan terhadap ISPA. Hasil penelitian ini tidak sejalan dengan penelitian (Fa and $\mathrm{Ct}, 2014$ ) imunisasi tidak lengkap mengalami ISPA yang parah yaitu sebesar 1.66 kali (1.18 - 2.34). Hal ini menunjukkan akan pentingnya imunisasi anak yang memadai dalam pencegahan penyakit, seperti campak, tuberkulosis, dan pertusis maupun ISPA. ${ }^{20}$

Penelitian lain imunisasi berhubungan terhadap ISPA pada balita di Puskesmas Wirobrajan Yogyakarta yaitu, balita yang tidak memiliki riwayat imunisasi dasar lengkap memiliki peluang 2,1 kali (CI $95 \%=1,098-4,253$ ) untuk sering terkena ISPA dibanding balita yang memiliki riwayat imunisasi dasar lengkap. ${ }^{21}$ Hasil penelitian ini status imunisasi tidak signifikan, Hal ini mungkin dikarenakan vaksin yang sudah tidak bagus sehingga fungsi vaksin tersebut menjadi gagal untuk memberikan kekebalan tubuh terhadap penyakit ataupun kemungkinan tenaga kesehatan dalam memberikan imunisasi tidak dilakukan dengan benar sehingga vaksin yang masuk ke dalam tubuh menjadi tidak berfungsi untuk mencegah penyakit. Menurut Sambominanga, dkk walaupun balita menerima imunisasi lengkap namun ISPA masih terjadi dikarenakan belum adanya vaksin yang dapat mencegah ISPA secara langsung. 
Faktor lain mempengaruhi juga terhadap daya tahan tubuh balita seperti status gizi balita, dan pemberian vitamin A serta lingkungan atau sanitasi didalam rumah memadai sehingga bila faktor tersebut dilakukan dengan baik akan mencegah ISPA terjadi, sehingga meskipun balita telah menerima imunisasi lengkap, kemungkinan untuk terjadi ISPA masih ada dengan adanya faktor lain tersebut. ${ }^{22}$ Penelitian ini terlihat bahwa keluarga miskin beresiko balitanya mengalami ISPA sebesar 1,3 kali (95\% CI 1,13 - 1,54) dibandingkan keluarga menengah, dan keluarga menengah beresiko balitanya untuk mengalami ISPA sebesar 1,3 kali (95\% CI 1,12-1,54) dibandingkan keluarga kaya. Hasil ini menunjukkan ada hubungan bermakna secara statistik dengan pvalue $0,000<0,05$. Hal ini sejalan penelitian dari (Azad, 2008) dan Penelitian lain berdasarkan Nigeria Demographic and Health Surveys (NDHS) pada tahun 2013 balita yang berasal dari keluarga miskin beresiko 1.78 kali $(95 \%$ CI 1.43 - 2.22) untuk terkena ISPA bila dibandingkan balita di keluarga kaya. ${ }^{23}$ Penelitian ini pada ibu bekerja informal balitanya beresiko sebesar 1,3 kali (95\% CI 1,07 - 1,47) dibandingkan ibu yang bekerja formal. Ibu yang bekerja di pekerjaan yang profesional / teknis menjadi faktor pelindung anak balitanya terhadap ISPA. Hal ini karena para ibu ini menghabiskan waktunya lebih sedikit atau tidak ada waktu untuk memasak makanan untuk keluarga dan sambil menggendong anak - anaknya, sehingga mengurangi paparan terhadap polusi udara dalam ruangan yang menjadi salah satu faktor lingkungan terjadinya ISPA. ${ }^{24}$

\section{Kesimpulan}

Penelitian ini ditemukan adanya hubungan signifikan BBLR terhadap ISPA setelah dikontrol oleh variabel confounding (jenis kelamin, usia bayi, tingkat kesjahteraan keluarga, pekerjaan ibu dan imunisasi). Faktor resiko yang menyebabkan ISPA dapat dicegah sedini mungkin salah satunya adalah menjaga kehamilan yang sehat pada ibu hamil agar memiliki status gizi baik sehingga saat melahirkan mencegah bayi untuk terlahir BBLR juga pentingnya menjaga pola hidup sehat dan menciptakan lingkungan didalam rumah yang bersih sanitasi dan ventilasi rumah memadai agar bayi atau balita terhindar dari paparan asap rokok maupun asap rumah tangga untuk mencegah terjadinya penyakit infeksi seperti ISPA. Hasil penelitian ini dapat dipertimbangkan untuk penelitian selanjutnya dan menyertakan variabel lain yang belum diteliti seperti usia ibu, keadaan lingkungan rumah (sanitasi, pencahayaan, kelembaban dan lainnya).

\section{Daftar Pustaka}

1. Simoes EAF, Cherian T, Chow J, Shahid- SA, Laxminarayan R, John TJ. Disease Control Priorities in Developing Countries/ : Acute Respiratory Infections in Children. Dis Control Priorities Dev Ctries. 2006; Chapter 25.

2. Black R, Morris S, Bryce J. Where and why are 10 Million Children Dying Every Year. Lancet. 2003;361.

3. Ramani VK, Pattankar J, Puttahonnappa SK. Acute respiratory infections among under-five age group children at urban slums of Gulbarga city: A longitudinal study. J Clin Diagnostic Res. 2016;10(5):LC08-LC13.

4. RISKESDAS. Riskesdas 2013. Jakarta Badan Penelit dan Pengemb Kesehat Dep Kesehat Republik Indones [Internet]. 2013;(Penyakit Menular):103.

5. Roth DE, Caulfield LE, Ezzati M, Black RE. Acute lower respiratory infections in childhood: opportunities for reducing the global burden through nutritional interventions. Bull World Health Organ. 2008;86(5):356-64.

6. Rice AL, Sacco L, Hyder A, Black RE. Malnutrition as an underlying cause of childhood deaths associated with infectious diseases in developing countries. Bull World Heal Organ. 2000;78(1207-21).

7. Welliver R. Review of Epidemiology and Clinical Risk factors for Severe Respiratory Syncytal Virus (RSV) Infection. J Pediatr. 2003; (November):S112-6.

8. Etiler N, Velipasaoglu S, Aktekin M. Incidence of acute respiratory infections and the relationship with some factors in infancy in Antalya, Turkey. Pediatr Int [Internet]. 2002;44(1):64-9.

9. Walter EC, Ehlenbach WJ, Hotchkin DL, Chien JW, Koepsell TD. Low Birth Weight and Respiratory Disease in Adulthood. Am J Respir Crit Care Med. 2009;180(2):176-80.

10. Lu YP, Zeng DY, Chen YP, Liang XJ, Xu JP, Huang SM, et al. Low birth weight is associated with lower respiratory tract infections in children with hand, foot, and mouth disease. Clin Lab. 2013;59(9-10):985-92.

11. GebregzabiherherY, Haftu A, Weldemariam S, Gebrehiwet $\mathrm{H}$. The Prevalence and Risk Factors for Low Birth Weight among Term Newborns in Adwa General Hospital, Northern Ethiopia. Obstet Gynecol Int 2017;2017(Figure 1).

12. Nejad NH, Pejhan A, Rakhshani MH, Hoseini BL. The incidence of low birth weight (LBW) and small- forgestational age (SGA) and its related factors in neonates, Sabzevar, Iran. Int J Pediatr. 2014;2(4):73-8.

13. Mayanda V. Hubungan Status Gizi Ibu Hamil dengan Berat Badan Lahir Rendah RSIA Mutia Sari Kecamatan Mandau. Menara Ilmu. 2017;XI(74):229-36.

14. Mariyatul, Triawanti, Noor MS. Hubungan Status Gizi Ibu amil dengan Kejadian Bayi Lahir Mati di Kabupaten Banjar Periode 2011 - 2012. Kedokt Univ Lambung Mangkurat. 2012;52-9.

15. Riana AA. Determinan Kejadian Bayi Berat Lahir Rendah (BBLR) di Wilayah Kerja Puskesmas Padang Selasa Kota Palembang Tahun 2017.2017.

16. Fibrila F. Hubungan Usia Anak, Jenis Kelamin dan Berat Badan Lahir Anak dengan Kejadian ISPA. J Kesehat Metro Sai Wawai Vol. 2015;VIII(2):8-13. 
17. Habibi M, Gayatri D, Bantas K. Faktor-faktor yang Mempengaruhi Kejadian Infeksi Saluran Pernapasan Akut (ISPA) pada Anak Berumur 12-59 Bulan di Puskesmas Kelurahan Tebet Barat, Kecamatan Tebet, Jakarta Selatan, Tahun 2013 Factors that Affecting Acute Respirator y Infection (ARI). 2010;1(1):23-7.

18. Christi H, Rahayuning D, Nugraheni S. Faktor-Faktor yng Berhubungan dengan Kejadian ISPA pada Bayi Usia 6-12 Bulan yang Memiliki Status Gizi Normal. 2015;3(April).

19. Molyneux. Respiratory Problems in The Tropics Manson's Tropical Diseases. University of London; 1996.

20. Ujunwa F, Ezeonu C. Risk factors for acute respiratory tract infections in under-five children in Enugu Southeast Nigeria. Ann Med Health Sci Res. 2014;4(1):95.

21. Hidayatullah LM, Helmi Y, Aulia H. Hubungan Antara Kelengkapan Imunisasi Dasar dan Frekuensi Infeksi Saluran Pernapasan Akut ( ISPA) pada Balita yang Datang Berkunjung ke Puskesmas Sekip Palembang 2014. J Kedokt dan Kesehat. 2016;3(3):182-93.
22. Sambominanga PS, Ismanto AY, Onibala F. Hubungan Pemberian Imunisasi dasar Lengkap dengan Kejadian Penyakit ISPA berulang pada Balita di Puskesmas Ranotana Weru Kota Manado. J Chem Inf Model. 2019;53(9):1689-99. 23. Akinyemi JO, Morakinyo OM. Household environment and symptoms of childhood acute respiratory tract infections in Nigeria, 2003-2013: A decade of progress and stagnation. BMC Infect Dis. 2018;18(1):1-12.

24. Tekle AG, Worku A, Birhane Y. Factors Associated with Acute Respiratory Infection in Children Under The Age of 5 years/: Evidence from the 2011 Ethiopia Demographic and Health Survey. Pediatr Heal Med Ther. 2015;129. 
Jurnal Epidemiologi Kesehatan Indonesia Vol. 5, No. 1, Juni 2021 